\title{
ENABLING ORGANIZATIONAL CHANGE - LEADERSHIP, COMMITMENT TO CHANGE AND THE MEDIATING ROLE OF CHANGE READINESS
}

\author{
Sinnappan Santhidran', V. G. R. Chandran ${ }^{2}$, Junbo Borromeo ${ }^{3}$ \\ ${ }^{1}$ Faculty of Creative Industry, Tunku Abdul Rahman University, \\ 46200 Petaling Jaya, Malaysia \\ ${ }^{2}$ Department of Development Studies, Faculty of Economics and Administration, \\ University of Malaya, 56300 Kuala Lumpur, Malaysia \\ ${ }^{3}$ Asian Institute of Management, Philippines, Eugenio López Foundation Building, \\ Joseph R. McMicking Campus, 123 Paseo de Roxas, MCPO Box 2095, \\ Makati City 1260, Metro Manila, Philippines \\ E-mails: ${ }^{1}$ santhidran@utar.edu.my; ${ }^{2}$ vgrchan@gmail.com (corresponding author); \\ 3junbo.borromeo@gmail.com
}

Received 22 September 2011; accepted 14 November 2011

\begin{abstract}
There has been little empirical analysis on the complex relationship between leadership, change readiness and commitment to change in the context of Asian countries. In this paper, we propose a research model to analyze the interrelationship between leadership, change readiness and commitment to change using the partial least square technique. Results of the study suggest that leadership positively and significantly affect change readiness but not commitment to change. Consequently, change readiness is found to significantly affect commitment to change. In other words, change readiness is found to mediate the relationship between transformational leadership and commitment to change. This may suggest that the influence of leadership is a sequential process affecting change readiness, and in turn, the commitment to change as opposed to the conventional belief that it affects both change readiness and commitment to change simultaneously. The implication of the study is further discussed.
\end{abstract}

Keywords: organizational change, leadership, commitment to change, change readiness, transformational leadership, Malaysia.

Reference to this paper should be made as follows: Santhidran, S.; Chandran, V. G. R.; Borromeo, J. 2013. Enabling organizational change - leadership, commitment to change and the mediating role of change readiness, Journal of Business Economics and Management 14(2): 348-363.

JEL Classification: M0, M21.

\section{Introduction}

Organizational change has been an issue of growing interest among scholars and practitioners (Armenakis, Bedeian 1999; Pettigrew et al. 2001; Burnes 2004; Whitely, A., Whitely, J. 2007). For Asian companies striving to become world leaders, change is 
imperative to achieve success in the globalized world that is attributed with stiff competition from both developed nations, and emerging economies such as China and India. Therefore, in many developing countries major organizational change is required to compete in this globalized world. Indeed, in Malaysia, emphasis on low cost labor advantage in sustaining competitiveness is less relevant nowadays. Competitiveness requires major organizational changes especially in the way organizations manage market and demand, innovative capability, technological change and rapid changes in many other aspects of a dynamic environment (Markovic 2008). All these efforts require organizations to make changes to their current operations and businesses including structure, processes, culture, vision and mission (Armenakis et al. 1993). However, many of these change efforts are unsuccessful (Kotter 1995; Judge, Douglas 2009) due to numerous factors that might have different degrees of influence in different contexts, e.g. different countries. Among these, issues of leadership, readiness and commitment to change are perceived to be important (Eisenbach et al. 1999; Armenakis et al. 1993). To date, despite the relevance of understanding change, the issues are largely neglected in Asia ${ }^{1}$. Empirical research on organizational change in the context of Asian countries is lacking, thus limiting any possible insights for managers and practitioners in Asia to rely on as a guide for management practice (Bruton, Lau 2008). Indeed, research tends to agree that evidence from the more stable environments, from the developed countries, can underestimate the relevant success of change efforts in developing countries (Chiaburu 2006). Owing to the differences in the cultural context, the validity of the previously established models and theories need to be empirically tested in the context of Asia. Consequently, the complexity of the relationship is less explored to provide sufficient understanding on how the variables affect each other, e.g., link between leadership and change process (Almaraz 1994; Eisenbach et al. 1999). Untangling this complex relationship helps provide sound managerial practice to improve the success of any change efforts. This indeed is expected to provide insights and lessons, both practical and managerial, on the relevance of leadership, change readiness and commitment to change that could limit transformation initiatives in developing countries. However, despite analyzing various aspects of change, to date there is no conclusive research that focuses on the interrelationship between leadership, change readiness and commitment to change.

Our objectives in this study were to examine employees' perceptions on readiness to change, commitment and leadership during transformation initiatives. We examine the fit between leadership, readiness and commitment. We attempt to answer the following questions: (i) how does transformational leadership affect change readiness? (ii) is there any relationship between change readiness and commitment to change? And (iii) is the effect of leadership on commitment to change direct or indirect? Therefore, this paper tends to provide conclusions to one of the key questions on the complexity of the relationship between leadership, change readiness and commitment to change. However, in doing so, we also made strategic decisions that involved tradeoffs (Kristof-Brown

\footnotetext{
${ }^{1}$ It is also less understood elsewhere due to the complexity and lack of research that goes beyond descriptive analysis (Armenakis, Bedeian 1999).
} 
et al. 2005) that consequently affect the generalization of the findings ${ }^{2}$. The strategic decisions involved deciding whether the survey should be administrated on a population of organizations or to take a case study approach by involving only a single organization. Being an exploratory study, in the case of Malaysia, we decided to take the case study and employee's perspective approach within a single organization. Indeed, we recognize that, at least at the early stage, controlling for industrial heterogeneity allows us to understand the issues in great detail. Also, since we are very confident that our selected organization is experiencing a high degree of change, it provides a useful context to explore the predictors and outcomes of coping with change. In addition, since our intention is not to analysis what drivers change at different organizations but to examine employee's motivation and willingness to change (since individual perception plays a fundamental role in change management) the case study approach deem to be appropriate. Although generalization is not possible, but yet, it does pave the way for us to comprehend the complex relationship between the variables. The findings of this study, indeed, suggest that a more systematic analysis in the context of Asia might be warranted in the future.

The next section provides the literature review and discusses the importance of readiness for change, commitment, culture and leadership for a successful organizational transformation. Section 3 describes the methodology of the study while Section 4 provides the empirical findings. Section 5 describes the implications of the study and the last section concludes the study.

\section{Research model, theoretical guide and hypotheses}

Figure 1 shows the research model established for this study whereby it examines the link between leadership, change readiness and commitment to change. The model contends that leadership influences both change readiness and commitment to change.

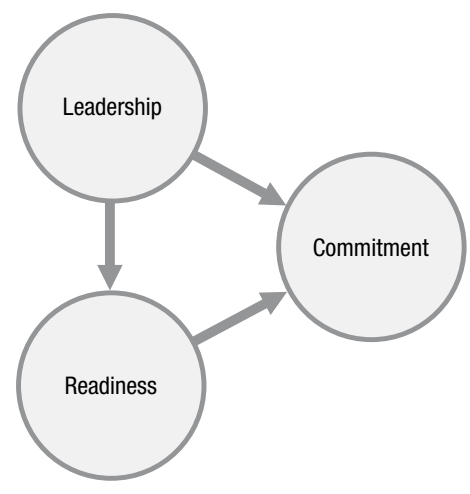

Fig. 1. Research Model Furthermore, change readiness is suggested to influence the commitment to change. It is also suggested that leadership influences readiness and in turn influences commitment to change. This relationship reflects the indirect role of leadership in influencing commitment to change. What we intend is not only to observe the direct link between leadership and commitment but also to unveil the complexity of such relationship by examining the mediating role of readiness.

Scholars (Coghlan 2000; Sullivan et al. 2002), as we do in this study, argue that understanding changes at individual level (e.g. individual process

\footnotetext{
${ }^{2}$ See Macri et al. (2002) for detailed survey on different levels of analysis (e.g. population of organizations, single organization and the individual level within an organization) in change management literature. Numerous studies have used single organizations as their level of analysis.
} 
changes - attitude to change, commitment to change and leadership) is an important part of managing organizational change. Therefore, in the next section, we describe the theoretical ground for each of the relationships, in specifics, and further establish the hypotheses of the study.

\subsection{Leadership and change readiness}

A review of literature on organizational change emphasizes the role of leadership (Armenakis et al. 1993). Scholars suggest numerous antecedents of change readiness, yet little empirical analysis is available (Wanberg, Banas 2000). Effective leaders tend to provide support that eventually changes the basic values, beliefs and attitudes of the employees so that they are ready to accept and understand the change efforts (Eisenbach et al. 1999; Podsakoff et al. 1996). Armenakis et al. (1993) argue that proactive managers who act as coaches and champions of change are more successful in preparing employees for the change efforts than managers who only monitor for signs of resistance to change. Interestingly, the leader's (or change agent's) attributes is also important in the process of creating readiness. Honesty, trustworthiness, sincerity and commitment are associated with the leader's reputation, serving as essential ingredients to promote change readiness. In addition, fostering acceptance to the proposed change requires leaders to communicate and provide quality leadership. Manz and Sims (2001) argue that transformational leaders facilitate the creation of necessary culture and shape the behavior of employees. This kind of leadership is able to create the vision and institutionalize the change efforts (Tichy, Devanan 1990). Trust in leaders and knowing that leaders are supportive of the change efforts is also important to ensure readiness (Walker et al. 2007). And, importantly, leaders should also have the skills to diagnose and develop capacity for change (Bossidy, Charan 2002).We, therefore, hypothesize the following:

H1: Leadership is positively related to change readiness.

\subsection{Leadership and commitment to change}

Despite creating readiness, leaders should also be able to encourage employees to commit to the change efforts. Esienbach et al. (1999), argue that leaders should possess the necessary skills and attributes to get employees involved in the transformation process. McShane and VonGlinow (2005), lucidly argue that leaders must be able to enable others to commit and contribute to the success of the change efforts. And, for such purpose, leaders should have certain skills and competence such as integrity, motivation, drive, emotional intelligence, self-confidence, intelligence and knowledge of the business. Similarly, Kotter (1995) emphasizes the issues of empowering and developing a sense of urgency to facilitate the change process including the commitment of employees. Ford, J. D. and Ford, L. W. (1994) establish that leaders should create change by attracting followers rather than creating dissatisfaction. In this effort, leaders should be supportive enough to ensure commitment of employees to the changes. Leaders also create the environment which is conductive for employees to commit to change efforts (Brown, Eisenhardt 1997). Indeed, commitment to change is associated with the amount of information that employees receive from change agents (Miller et al. 1994). On the 
other hand, passive leaders would not be able to provide sufficient information and actively prepare employees for change. We, therefore, hypothesize that:

H2: Leadership is positively related to commitment to change.

\subsection{Change readiness and commitment to change}

Having the right mindset for change is an important determinant of the success of any form of transformation. The pioneering work of Lewin $(1947,1951)$ suggests that for change to be successful it is important that negative attitudes towards change are overcome to avoid any resistance to change. Emphasizing on the process of change, Armenakis et al. (1993) suggest that for a successful change there is a need to prepare employees for the change. This involves proactive attempts by the change agent to change the belief, attitude and behavior of the employees that will be involved in the change effort. Indeed, Walker et al. (2007) argue that change agents have to prepare employees for change via open and honest communication. Effectiveness in implementing change is affected by the beliefs of the change targets about change. Similarly, in the case of Estonia, Ruth (2004) stressed that the failure of changes in many companies was due to the lack of readiness to change among employees. As a whole, it is argued that commitment to change depends on the understanding and the beliefs on the proposed change. Therefore, we hypothesize that:

H3: Change readiness positively affects commitment to change.

\subsection{Mediating role of change readiness between leadership and commitment}

Leaders are influential in the sense that they will be able to motivate by improving commitment and readiness for change (Whelan-Berry et al. 2003). However, despite the argument that leadership has a direct influence on readiness and commitment to change, it can also be argued that leadership has an indirect influence on commitment to change. In other words, although leadership may influence commitment to change, leadership may as well influence the change readiness that is necessary to prepare the change targets and consequently influence the commitment to change. That is, change readiness can be facilitated by leadership, and in turn, influence commitment to change. Based on the past empirical evidence (Eisenbach et al. 1999; Podsakoff et al. 1996; Armenakis et al. 1993) that stresses the influence of leadership on readiness and the influence of readiness on commitment to change (Lewin 1947, 1951; Walker et al. 2007), one can expect an indirect relationship of leadership on commitment to change with change readiness playing the mediating role. To test for any existence of the mediating role of change readiness we hypothesize the following:

H4: Change readiness mediates the impact of leadership on commitment to change.

\section{Methodology}

\subsection{Participants and procedure}

Data was collected from one well-established large energy organization (local, not multinational) in Malaysia. This organization was selected because it has recently undergone a significant transformation in its culture, structure, technology, and systems. This 
is due to the desire to improve management control over work processes, customers demand and competition. We only focused on the employees working in organization's headquarters in Kuala Lumpur, Malaysia and excluded other branch offices located in different part of Malaysia. This is due to the fact that employees at the headquarters office were directly involved and impacted by organizational changes. Among the most immediate and visible change include vision change, strategy change, system change, process improvement, and restructuring of organization units were the major changes of the organization. Respondents were also asked to indicate the types of changes that their organization had undergone for the past five years. To validate, their responses, we interviewed the head and change leaders to ensure that those changes are, indeed, implemented in their organization. In addition, a few selected respondents were met at different time periods for a brief interview before the data collection. This was to check the content validity of the questionnaires and to gather first-hand information on the types of organizational change implemented in the selected organization. Since this study focuses on the employee's perspective on leadership, readiness and commitment for change, we excluded data obtained from those involved in initiating and planning the change (e.g. senior management). For this study, we only include middle management employees $(N=300)$, executives and supervisors, who are directly impacted by organizational change. With the support of the Human Resource Manager, time schedule was arranged for the respondents to fill up the survey forms. A total of 200 questionnaires were distributed randomly to this group of potential respondents and seventy three (73) complete responses were received and used for analysis (36.5\% response rate). In terms of working experience in the organization, majority of the respondents $(38 \%)$ have 16-30 years of experience, while others have 8-15 (34\%) and 3-7 years of experience $(21.9 \%)$ respectively. The remaining have more than 30 years of experience. As whole, female respondents represent $49 \%$ of the total sample, and in terms of marital status, $85 \%$ of respondents are married.

\subsection{Survey instrument}

The survey on organizational change consists of several sections. Section A outlines the initiatives for changes especially types and reasons for the change efforts while the other sections measures the variables of interest of the study namely readiness for change, commitment to change as well as leadership. The variable measurements were developed by reviewing definitions established in the past literature and adapting measures of construct that have been validated by other studies. Several definitions exist to reflect the construct of readiness for change. Lewin (1951) describes organization change as a process of unfreezing, moving and freezing.

Change readiness is perceived as a process of unfreezing where members of the organization are prepared for change efforts. Miller et al. (1994) define readiness for change as openness to change which includes the support for change and positive effects of potential consequences of change. Amerkias et al. (1993) refer to the cognitive precursor to the behavior of either resistance to or support for change efforts. Despite the use of different definitions in the previous research, consensus emerged in that readiness 
for change is commonly referred to as "a state of mind reflecting a willingness and receptiveness to change in the way one thinks" (Bernerth 2004: 39).

In this study, Readiness for change was measured using 6 items from the Change-Related Self-Efficacy Scale (Holt et al. 2007). The scale uses a 5-point agreement-disagreement Likert format with $1=$ Strongly Disagree and $5=$ Strongly Agree. Commitment to change can be assessed by affective responses to change efforts (Walker et al. 2007). Commitment to change was measured using 6 items from the Affective Commitment to Organizational Change Scale (Herscovitch, Meyer 2002). The scale used a 5-point agreement-disagreement Likert format with $1=$ Strongly Disagree to $5=$ Strongly Agree. Transformational, charismatic and visionary leaders are increasingly important to manage change effectively (Eisenbach et al. 1999). More importantly, leader's capabilities drive the change processes. In measuring leadership ${ }^{3}$, we concentrated on the favorable attributes and capabilities that are of importance for readiness and commitment to change. We asked the respondents to indicate what they think about the change agents on those attributes and capabilities. In total 15 items were included to measure the leadership construct (see Appendix A). We used a 5-point scale with $1=$ rarely to $5=$ almost always. Questionnaire items measuring each of construct are shown in Table 1.

Table 1. Measurement items

\begin{tabular}{cc}
\hline Construct & \multicolumn{1}{c}{ Scale } \\
\hline Commitment to Change & $1=$ strongly disagree; \\
$5=$ strongly agree
\end{tabular}

I believed in the value of the change/s. (C1)

This change was a good strategy for this organization. (C2)

I think that management made a mistake by introducing

the change/s. (C3)

The change/s served an important purpose. (C4)

Things would be better without the change/s. (C5)

The change/s was/were not necessary. (C6)

I supported the change/s. (C7)

\section{Change Readiness}

$1=$ strongly disagree;

$5=$ strongly agree

I was able to perform successfully after the change/s was/were made. (R1)

I had the skills that were needed to make the change/s work. (R2)

When we implemented the change/s, I felt I could handle them

with ease. (R3)

\footnotetext{
${ }^{3}$ Eisenbach et al. (1999) provides interesting account on the issue of transformational leadership that is essential for effective change management. Other literatures (see Nadler and Tushman 1989; Podiakoff et al. 1996; Tichy and Devanna 1990) on leadership also provide sufficient information in developing the leadership construct. Kouzes and Posner (1995) measures five important dimensions of leadership practices that include model the way, inspire a shared vision, challenge the process, enable others to act, and encourage the heart. We used these dimensions in our questionnaire.
} 
End of Table 1

\begin{tabular}{|c|c|}
\hline Construct & Scale \\
\hline \multicolumn{2}{|c|}{$\begin{array}{l}\text { When I heard about the change/s, I thought it suited my skills perfectly. } \\
\text { (R4) }\end{array}$} \\
\hline \multicolumn{2}{|c|}{$\begin{array}{l}\text { After the change/s was/were implemented, I was confident I would be } \\
\text { able to do my job. (R5) }\end{array}$} \\
\hline \multicolumn{2}{|c|}{ I expected to succeed after the change/s was/were implemented. (R6) } \\
\hline Leadership & $\begin{array}{l}1=\text { rarely; } \\
5=\text { almost always }\end{array}$ \\
\hline
\end{tabular}

Set a personal example of what he or she expected from others. (L1)

Praised people for a job well done. (L2)

Challenged people to try out new and innovative approaches

to their work. (L3)

Described a compelling image of what our future could be like. (L4)

Actively listened to diverse points of view. (L5)

Made it a point to let people know about his or her confidence

in their abilities. (L6)

Searched for innovative ways to improve on what we do. (L7)

Appealed to others to share an exciting dream of the future. (L8)

Treated others with dignity and respect. (L9)

Followed through on the promises and commitments that he or she

made. (L10)

Asked "What can we learn?" when things did not go as expected. (L11)

Supported the decisions that people made on their own. (L12)

Experimented and took risks even when there was a chance

of failure. (L13)

Was enthusiastic and positive about future possibilities. (L14)

Gave the members of the team lots of appreciation and support

for their contributions. (L15)

\subsection{Techniques of analysis}

The complex relationship between leadership, change readiness and commitment to change is examined using partial least square (PLS) method. PLS method offers a number of advantages. PLS is suitable for theory confirmation (Chin 1998) whereby focus is on the theoretical development compared to other methods (LISREL) that is preferred for confirmatory testing of theoretical models (Gefen et al. 2000). In other words, PLS is more appropriate if the study intends to involve in predictive analysis exploring complex problems that have limited theoretical knowledge. PLS only requires small size of sample (Chin 1998; Hulland 1999) and does not impose strict requirements on distribution constraint. 


\section{Findings}

PLS analysis involves two stages. In the first stage, we tested the measurement model by assessing the validity and reliability of the construct. Items loading more than 0.5 (Janz, Prasarnphanich 2003; Saade 2007) suggest item reliability while the Cronbach's alpha values should exceed 0.6 for the construct reliability (Nunnally 1967). The convergent validity can be assessed using composite reliability (CR) and average variance extracted (AVE). The value of CR and AVE should be greater than 0.6 and 0.5 respectively (Bagozzi, Yi 1988).

In the second stage, the structural model was tested by estimating the significance of the path coefficient using $t$-test. The use of variance explained $\left(R^{2}\right)$ of the endogenous variable indicates the model fit. As suggested by Chin (1998), the relationship is examined using the bootstrapping procedure with 500 sub-samples. We first conducted PLS analysis to examine item reliability. Table 2 reports the item loading and the value of Cronbach's alpha. We removed items that have loading less than 0.5. Since both the values exceed the recommended values, the overall measurement items have adequate

Table 2. Item loading and Cronbach's Alpha $(\mathrm{N}=73)$

\begin{tabular}{cccc}
\hline Construct & Item Loading & $t$-statistics & Cronbach's Alpha \\
\hline Commitment to Change & & & 0.804 \\
\hline (C1) & $0.890^{* *}$ & 33.489 & \\
(C3) & $0.531^{* *}$ & 3.667 & \\
(C4) & $0.784^{* *}$ & 17.423 & \\
(C7) & $0.909^{* *}$ & 45.418 & 0.839 \\
\hline Change Readiness & & & \\
(R1) & $0.817^{* *}$ & 18.812 & \\
(R2) & $0.807^{* *}$ & 19.689 & \\
(R4) & $0.790^{* *}$ & 14.382 & \\
(R5) & $0.870^{* *}$ & 26.996 & \\
\hline Leadership & & & \\
(L1) & $0.820^{* *}$ & 18.830 & \\
(L2) & $0.816^{* *}$ & 19.767 & \\
(L3) & $0.766^{* *}$ & 12.008 & \\
(L4) & $0.796^{* *}$ & 16.725 & \\
(L5) & $0.819^{* *}$ & 21.368 & \\
(L6) & $0.802^{* *}$ & 13.635 & \\
(L7) & $0.857^{* *}$ & 22.385 & \\
(L8) & $0.801^{* *}$ & 20.297 & \\
(L9) & $0.704^{* *}$ & 10.162 & \\
(L10) & $0.835^{* *}$ & 25.536 & \\
(L12) & $0.754^{* *}$ & 15.183 & \\
(L13) & $0.716^{* *}$ & 10.897 & \\
\hline
\end{tabular}

Note: Few items were removed due to low loading values. ${ }^{* *} p<0.01$. 
item reliability. We further assessed the convergent validity by examining composite reliability (CR) and average variance extracted (AVE) from the measures. The AVE and $\mathrm{CR}$ are well above the recommended value confirming the convergent validity (see Table 3). In addition, the square roots of average variance extracted are greater than the levels of correlations of the respective construct confirming discriminant validity. Since the correlation coefficients are below the cutoff of 0.8 (Bryman, Cramer 1994), we can rule out any possibility of multicollinearity.

Table 3. Convergent and discriminant validity $(\mathrm{N}=73)$

\begin{tabular}{cccc}
\hline Variables & Commitment & Readiness & Leadership \\
\hline Commitment & 0.793 & & \\
\hline Readiness & 0.652 & 0.822 & 1 \\
\hline Leadership & 0.339 & 0.444 & 0.627 \\
\hline AVE & 0.629 & 0.675 & 0.953 \\
\hline CR & 0.867 & 0.892 & 3.544 \\
\hline Mean & 4.102 & 3.877 & 0.658 \\
\hline SD & 0.521 & 0.468 &
\end{tabular}

Note: the italic numbers in the diagonal row are square roots of average variance extracted.

Table 4 reports the results of our model and hypothesized relationships. The $R$-square values $(0.197$ for readiness and 0.429 for commitment) suggest a good model fit. The results indicate that leadership $(\beta=0.444, \mathrm{p}<0.001)$ has a statistically significant relationship on readiness. This result is in accordance with $H 1$ predictions. However, there is no support on the significance of the proposed relationship between leadership and commitment to change, thus $\mathrm{H} 2$ is not supported. This may suggest that leaders failed to attract followers (Ford, J. D., Ford, L. W. 1994) and may have created dissatisfaction. One possible explanation lies in the Asian's cultural dimension, in particular Malaysia. Malaysia's cultural dimension, specifically power distance, remain high (Lim 2001), thus making Malaysian leaders hard to reinforce employee's commitment to change. Indeed, Rees and Johari (2010), assertion that Malaysian workers tend to respect elders and hierarchy might explain why leadership significantly influences readiness to change but not commitment to change directly. Employees tend to be loyal in taking directive from their leaders by displaying high readiness to change. This findings raises uncertainty on the framework applied to the developed countries that posit a strong relationship between leadership and commitment to change, thus contributing to the existing knowledge on the link in developing countries. In contrast, change readiness ( $\beta=0.626, p<0.001)$ extracts significant influence on commitment to change. This finding is consistent with $H 3$. This is in accordance with the claim by Armenakis et al. (1993) that creating readiness, which is described as employee's beliefs, attitudes and intentions, is important and along the way change agents must have the credibility and interpersonal in the readiness creation process. As a whole, the study confirms the importance of leadership on readiness $(H 1)$ and readiness on commitment to change $(H 3)$. 
In testing the mediating role of change readiness, we estimated the model by dropping change readiness construct from the model. We can conclude that change readiness fully mediates the relationship between leadership and commitment to change if the path coefficient of leadership increases and shows significant relationship with commitment to change. Baron and Kenny (1986) suggest examining the mediating role of a variable in the following ways. The variable is considered as a mediating variable if the independent variable (leadership) is significant on the mediating variable (readiness) and the mediating variable (readiness) is significant on the dependent variable (commitment). In addition, a variable will be fully mediating if the independent variable (leadership) has no influence on the dependent variable (commitment) when the mediating variable (readiness) is controlled in the model. It is said to be partially mediating when the significance of leadership on the commitment is less than the significance of readiness on commitment.

We compare the results of Panel I and II in Table 4. In our case, leadership is found to significantly influence commitment $(\beta=0.365, \mathrm{p}<0.001)$ without the mediating variable (see Panel II). However, when we add readiness as the mediating variable, leadership becomes insignificant $(\beta=0.062$ ) to commitment to change. We, therefore, confirm that readiness acts as the fully mediating variable between leadership and commitment to change, thus supporting $H 4$ of this study.

Table 4. Results of hypotheses testing $(\mathrm{N}=73)$

\begin{tabular}{lcccc}
\hline \multicolumn{5}{c}{ Panel I: Model with mediating role } \\
\hline Hypotheses & $\beta$ & t-statistics & $\mathrm{R}^{2}$ & Results \\
\hline HI: Leadership $\rightarrow$ change readiness & 0.444 & $6.145^{* *}$ & 0.197 & Supported \\
H2: Leadership $\rightarrow$ commitment to change & 0.062 & 0.830 & & Not Supported \\
H3: Change readiness $\rightarrow$ commitment to change & 0.626 & $11.167^{* *}$ & 0.429 & Supported \\
\hline
\end{tabular}

Pane II: Model without mediating role (change readiness)

\begin{tabular}{lllll}
\hline Leadership $\rightarrow$ commitment to change & 0.365 & $6.0251^{* *}$ & 0.133 & \\
H4: Mediating role of readiness & & & & Supported \\
\hline
\end{tabular}

Notes: ${ }^{+}$To assess whether readiness acts as a fully mediating variable we compare the model with and without a readiness variable. If leadership exerts significant influence on commitment without the mediating variable and becomes insignificant after adding the mediating variables than we can confirm that readiness is a fully mediating variable. ${ }^{* *} \mathrm{p}<0.001$.

What is the explanation for this rather contradicting result? First, it may suggest that without readiness it will be harder for leaders to convince and pursue employees to commit to the change efforts. The second answer is that readiness is required to minimize the resistance to change ${ }^{4}$ that eventually allows greater commitment to change by em-

\footnotetext{
${ }^{4}$ See Armenakis et al. (1993) for a complete review on the differences between readiness and resistance to change. The study also provides reviews on the link between readiness and resistance to change. Similarly, the term unfreezing process (Lewin 1947) also involves creating awareness or readiness.
} 
ployees. Thus, leaders planning to directly influence employees' commitment may lead to failure. Indeed, Armenakis et al. (1993) argued that leaders who screen and monitor for change-resisting behavior are unlikely to be successful in enforcing commitment. But, leaders' attributes that favor and facilitate readiness would consequently encourage employees to commit to change efforts by minimizing the resistance (Armenakis et al. 1993).

\section{Discussion}

This study examines the effects of leadership and change readiness on commitment to change and the effects of leadership on change readiness respectively. The results of the study indicate that leadership has a positive and significant relationship with change readiness. In addition, the study fails to find any direct relationship between leadership and commitment to change. However, leadership is found to affect commitment to change indirectly through change readiness. It is found that leadership exerts significant effect on readiness, and in turn, affects commitment to change.

It is therefore important for managers to understand the sequence of the effects of leadership. Leaders must first prepare the employees to be ready for change and subsequently prepare the employees to commit to change efforts. In other words, leaders who try to directly intensify the commitment to change will not be able to successfully transform the organization without initially creating the readiness for change. The resulting effect is for managers to focus on readiness before any attempts to improve commitment to change. Less emphasis on issues of preparing employees for change will ultimately lead to failure in change efforts even with improved leadership. Neal (2008), using a case study, suggested that a practical guide is for leaders (CEOs and change agents) to offer a clear and consistent communication to assist employees through the change process.

Besides providing insights to managers on the interrelationship between leadership, change readiness and commitment to change, this study has also made theoretical as well as new contributions in the sense that it may direct future research in these areas. Indeed, this study contributes to the organizational change literature that remains relatively fragmented (Armenakis, Bedeian 1999) by examining the mediating role of readiness. Despite evidence suggesting the effects of leadership on commitment, in this study, we discovered that the order of effects is not direct. The sequence of influence follows the following orders: leadership influences readiness, and in turn, readiness influences commitments. Leadership has indirect effect on commitment.

As usual, the present study is not without any caveats. One limitation is the use of single organization. Caution should, indeed, be exercised when interpreting the results as generalization is not possible. Second, this study lacks the longitudinal perceptive and relies only on employee's responses as the unit of analysis. Therefore, to strengthen the theoretical contribution more research is required. We strongly suggest the replication and application of the research model in different settings (e.g. different countries, industries, levels of analysis) to validate the theoretical contribution of this study. Perhaps 
a case study, qualitative approach, is also needed to deduce practical reasoning for the observations made through the data analysis of this study. Despite the limitations, at least, with the new insights from this study it is hoped that it will inspire further empirical work within this area to provide managers with informed decisions.

\section{Conclusion}

Research on organizational change is not completely understood in the developing countries especially with respect to the process of change itself. The complexity of the organizational process cannot be explained just by using comprehensive one way predictive models. What is required is to understand the inter-linkages among the variables of the study. This study contributes to understanding the interrelationship between leadership, change readiness and commitment to change using the partial least square methodology. It was once thought that leadership affects commitment directly. But, empirical evidence in our study suggests the opposite. However, the generalization made in our study is limited to the organization under study. More research is needed to explore the issues in greater detail. However, we believe that this study has paved the path for future research to consider and expand the link between leadership, change readiness and commitment to change.

\section{Acknowledgements}

The authors would like to thank Haji Zulkifli Baharom of the Kelab AIM Malaysia, and the staff of the human resource division of the selected organization, for assisting and facilitating the process of data collection. We also thank Prof. Regina Hechanova for including Malaysia in her project on organizational change in Asia. Support from Asian Institute of Management, Universiti Tunku Abdul Rahman is greatly appreciated. We appreciate the comments from the reviewers as well as the journal editors.

\section{References}

Almaraz, J. 1994. Quality management and the process of change, Journal of Organizational Change Management 7(2): 6-14. http://dx.doi.org/10.1108/09534819410056096

Armenakis, A. A.; Bedeian, A. G. 1999. Organizational change: a review of theory and research in the 1990s, Journal of Management 25(3): 293-315. http://dx.doi.org/10.1177/014920639902500303

Armenakis, A. A.; Harris, S. G.; Mossholder, K. W. 1993. Creating readiness for organizational change, Human Relations 46(6): 681-703. http://dx.doi.org/10.1177/001872679304600601

Bagozzi, R. P.; Yi, Y. 1988. On the evaluation of structural equation models, Journal of the Academy of Marketing Science 16(1): 74-94. http://dx.doi.org/10.1007/BF02723327

Baron, R. M.; Kenny, D. A. 1986. The moderator-mediator variable distinction in social psychological research: conceptual, strategic, and statistical considerations, Journal of Personality and Social Psychology 51(6): 1173-1182. http://dx.doi.org/10.1037/0022-3514.51.6.1173

Bernerth, J. 2004. Explaining our understanding of the change message, Human Resource Development Review 3(1): 36-52. http://dx.doi.org/10.1177/1534484303261230

Bossidy, L.; Charan, R. 2002. Execution: the Discipline of Getting Things Done. New York, NY: Crown Business. 
Brown, S. L.; Eisenhardt, K. M. 1997. The art of continuous change: linking complexity theory and time-paced evolution in relentlessly shifting organizations, Administrative Science Quarterly 42(1): 1-34. http://dx.doi.org/10.2307/2393807

Bruton, G. D.; Lau, C. M. 2008. Asian management research: status today and future outlook, Journal of Management Studies 45(3): 636-659. http://dx.doi.org/10.1111/j.1467-6486.2007.00758.x Bryman, A.; Cramer, D. 1994. Quantitative Data Analysis for Social Scientists. New York: Routledge.

Burnes, B. 2004. Managing Change. $2^{\text {nd }}$ ed. London: FT/Prentice-Hall.

Chiaburu, D. S. 2006. Managing organizational change in transition economies, Journal of Organizational Change Management 19(6): 738-746. http://dx.doi.org/10.1108/09534810610708387

Chin, W. 1998. The partial least squares approach to structural equation modeling, in G. A. Mrcoulides (Ed.). Modern Methods for Business Research. Hillsdale, NJ: Lawrence Erlbaum Associates, 295-336.

Coghlan, D. 2000. The interlevel dynamics of systemic learning and change, Reflections: The SOL Journal 2(2): 67-71. http://dx.doi.org/10.1162/15241730051092028

Eisenbach, R. K.; Watson, K.; Pillai, R. 1999. Transformational leadership in the context of organizational change, Journal of Organizational Change Management 12(2): 80-88.

http://dx.doi.org/10.1108/09534819910263631

Ford, J. D.; Ford, L. W. 1994. Logics of identity, contradiction, and attraction in change, Academy of Management Review 19(4): 756-785.

Gefen, D.; Straub, D. W.; Boudreau, M. C. 2000. Structural equation modeling and regression: guidelines for research practice, Communications of the Association for Information Systems 4(7): 1-79.

Herscovitch, L.; Meyer, J. P. 2002. Commitment to organizational change: extension of a threecomponent model, Journal of Applied Psychology 87: 474-487.

http://dx.doi.org/10.1037/0021-9010.87.3.474

Holt, D. T.; Armenakis, A. A.; Feild, H. S.; Harris, S. G. 2007. Readiness for organizational change: the systematic development of a scale, Journal of Applied Behavioural Science 43(2): 232-255. http://dx.doi.org/10.1177/0021886306295295

Hulland, J. 1999. Use of partial least square (PLS) in strategic management research: a review of four recent studies, Strategic Management Journal 20: 195-204.

http://dx.doi.org/10.1002/(SICI)1097-0266(199902)20:2<195::AID-SMJ13>3.0.CO;2-7

Janz, B. D.; Prasarnphanich, P. 2003. Understanding the antecedents of effectiveness knowledge management: the importance of a knowledge-center culture, Decision Sciences 34(2): 351-384. http://dx.doi.org/10.1111/1540-5915.02328

Judge, W.; Douglas, T. 2009. Organizational change capacity: the systematic development of a scale, Journal of Organizational Change Management 22(6): 635-649.

http://dx.doi.org/10.1108/09534810910997041

Kotter, J. P. 1995. Leading change: why transformational efforts fail, Harvard Business Review (March/April): 59-67.

Kouzes, J.; Posner, B. 1995. The Leadership Challenge. San Francisco, CA: Jossey-Bass.

Kristof-Brown, A. L.; Zimmerman, R. D.; Johnson, E. C. 2005. Consequences of individual's fit at work: a meta-analysis of person-job, person-organization, person-group, and person-supervisor fit, Personnel Psychology (58): 281-342. http://dx.doi.org/10.1111/j.1744-6570.2005.00672.x

Lewin, K. 1947. Frontiers in group dynamics, Human Relations 1: 5-41.

http://dx.doi.org/10.1177/001872674700100103 
Lewin, K. 1951. Field Theory in Social Sciences. New York, NY: Holt.

Lim, L. 2001. Work-related values of Malays and Chinese Malaysians, International Journal of Cross Cultural Management 1(2): 209-226. http://dx.doi.org/10.1177/147059580112005

Macri, D. M.; Tagliaventi, M. R.; Bertolotti, F. 2002. A grounded theory for resistance to change in a small organization, Journal of Organization Change Management 15(3): 292-310.

http://dx.doi.org/10.1108/09534810210429327

Manz, C.; Sims, H. P. 2001. The New Superleadership. Koehler Publishers Inc.

Markovic, M. R. 2008. Managing the organizational change and culture in the age of globalization, Journal of Business Economics and Management 9(1): 3-11.

http://dx.doi.org/10.3846/1611-1699.2008.9.3-11

McShane, S.; VonGlinow, M. A. 2005. Organizational Behavior: Emerging Realities for the Workplace Revolution. $3^{\text {rd }}$ ed. New York: McGraw-Hill.

Miller, V. D.; Johnson, J. R.; Grau, J. 1994. Antecedents to willingness to participate in a planned organizational change, Journal of Applied Communication Research 26: 59-80.

Nadler, D. A.; Tushman, M. L. 1989. Leadership for organizational change, in S. Mohrman, G. Jr. Ledford, T. Cummings, E. Lawler, and Associates (Eds.). Large-scale Organizational Change. San Francisco, CA: Jossey-Bass, 100-119.

Neal, A. 2008. Preparing the organization for change, Strategic Human Resource Review 7(6): 30-35.

Nunnally, J. C. 1967. Psychometric Theory. New York: McGraw-Hill. http://dx.doi.org/10.1108/14754390810906418

Pettigrew, A. M.; Woodman, R. W.; Cameron, K. S. 2001. Studying organizational change and development: challenges for future research, Academy of Management Journal 44(4): 697-713. http://dx.doi.org/10.2307/3069411

Podsakoff, P. M.; MacKenzie, S. B.; Bommer, W. H. 1996. Transformational leader behaviors and substitutes for leadership as determinants of employee satisfaction, commitment, trust, and organizational citizenship behaviors, Journal of Management 22: 259-298.

Rees, C. J.; Johari, H. 2010. Senior managers' perceptions of the HRM function during times of strategic organizational change: case study evidence from a public sector banking institution in Malaysia, Journal of Organizational Change Management 23(5): 517-536.

http://dx.doi.org/10.1108/09534811011071261

Ruth, A. 2004. Process model for organizational change: a study of Estonian companies, Journal of Business Economics and Management 5(3): 109-117.

Saade, R. G. 2007. Dimensions of perceived usefulness: toward enhanced assessment, Decision Sciences Journal of Innovative Education 5(2): 289-310.

http://dx.doi.org/10.1111/j.1540-4609.2007.00142.x

Sullivan, W.; Sullivan, R.; Buffton, B. 2002. Aligning individual and organizational values to support change, Journal of Change Management 2(3): 247-254. http://dx.doi.org/10.1080/738552750

Tichy, N. M.; Devanna, M. A. 1990. The Transformational Leader. New York, NY: John Wiley.

Walker, H. J.; Armenakis, A. A.; Bernerth, J. B. 2007. Factors influencing organizational change efforts: an integrative investigation of change content, context, process and individual differences, Journal of Organizational Change Management 20(6): 761-773.

http://dx.doi.org/10.1108/09534810710831000

Wanberg, C. R.; Banas, J. T. 2000. Predictors and outcomes of openness to change in a reorganizing workplace, Journal of Applied Psychology 85(4): 132-142.

http://dx.doi.org/10.1037/0021-9010.85.1.132 
Whelan-Berry, K. S.; Gordon, J. R.; Hinings, C. R. 2003.Strengthening organizational change processes: recommendations and implications from a multilevel analysis, Journal of Applied Behavioral Science 39(2): 186-207. http://dx.doi.org/10.1177/0021886303256270

Whitely, A.; Whitely, J. 2007. Core Values and Organizational Change: Theory and Practice. London: World Scientific.

Sinnappan SANTHIDRAN. An Assistant Professor teaches research methods and statistics for postgraduates and undergraduates. He is the Head of Program for Masters of Communication. He received his PhD in Human, Technology and Industrial Development from University of Malaya, Kuala Lumpur, Malaysia. He was a visiting scholar at Donahue Institute, University of Massachusetts, Amherst and Institute of Global Studies, University of Delaware, Newark in 2011. His research focuses primarily on creativity and innovation, change management, motivation, work environment, social psychology and political psychology.

V. G. R. CHANDRAN. Associate Professor at the Department of Development Studies, University of Malaya, Malaysia. He has also worked as a Principal Analyst of Economics and Policy Studies with Malaysian Industry-Government Group for High Technology, Prime Minister's Department, Malaysia. He holds a PhD in Economics and has held positions as a consultant and research associate with several international institutions. He conducts and leads research projects on industrial competitiveness, innovation and technology policy.

Horacio M. (Jumbo) BORROMEO. Professor and the Associate Dean of the W. SyCip Graduate School of Business. His expertise is in organizational behavior. He teaches the Human Behavior in Organizations and the Management Communication courses in the MBA program. He also teaches regularly in executive education programs. His current research interest is emotional intelligence in organizational communications. He has designed and conducted management development and leadership seminars, and team-building and strategic planning workshops for a wide variety of companies and organizations in the Philippines and throughout the ASEAN region. 